\title{
The last botnet
}

You've got mail.

Perhaps it was inevitable that our robotic proxies would start sending us spam. Even so, for the Interplanetary Internet to succumb to a virus just as civilization received a coup de grâce from the biological variety constitutes an irony of astronomical proportions.

Clare Tomblin's penultimate e-mail explains how we got into this mess.

From: Clare Tomblin [clare_tomblin@mars. net]

To: George Benoit [george_benoit@lunar.net] Subject: Hope you like tinned meat! Dear George

To keep my mind off things, I've done some digging. It looks like some nameless Agency twonk decided to upgrade the operating system of every unmanned spacecraft 'out there'. Sadly, it looks like our 'friend' forgot to patch the security holes.

I hope the bastard suffered!

Now I'll have to figure out how to protect your array.

Much love.

Clare

Like a handful of other Moon and Mars personnel, Clare and I elected not to board the evacuation flights. Neither of us had loved ones to bury back on Earth, nor did we plan to experience the ghastly, lung-melting death that the Chester virus inflicted on $99.9 \%$ of humanity. The view of Earth's nightside through the Shackleton Base telescope confirmed that the remaining $0.1 \%$ won't be enough to keep the lights burning.

Strangely, most of those who stayed behind waited no more than a day or two before clambering into their spacesuits. Seems they wanted one last view of Mother Earth before cracking their helmet seals.

But for Clare and me, isolation worked wonders. The irreducible time lag provided the perfect catalyst for long-distance love. Trouble was, by last Saturday night our relationship had become hamstrung by denial-of-service attacks.

I'd spent eight hours tinkering with the $\mathrm{CO}_{2}$ scrubbers when I realized I hadn't heard the chimes from my PC heralding Clare's Midnight Kiss. That got my attention, albeit belatedly, because she'd never forgotten before, not since we became an 'item'.

'Midnight Kiss' as in an e-mail containing romantic small talk; not a video clip of her pouting lips or, God forbid, a VR feely. Wisely, we'd agreed to practise safe text rather than endure the frustrations induced by more intimate forms of communication.

I checked my inbox but found nothing.

In contrast, my spam folder contained hundreds of new arrivals, mostly of the 'make her squeal' variety. Despite these unwanted reminders that I would never meet Clare in the flesh, I couldn't bring myself to empty the folder. Perhaps my subconscious had decided that any message was better than none.

Naturally enough, I sent Clare an e-mail. After four hours without a reply, I followed up with another e-mail ... and another.

Lucky Number Seven got a response, unfortunately of the 'mailbox-full' variety.

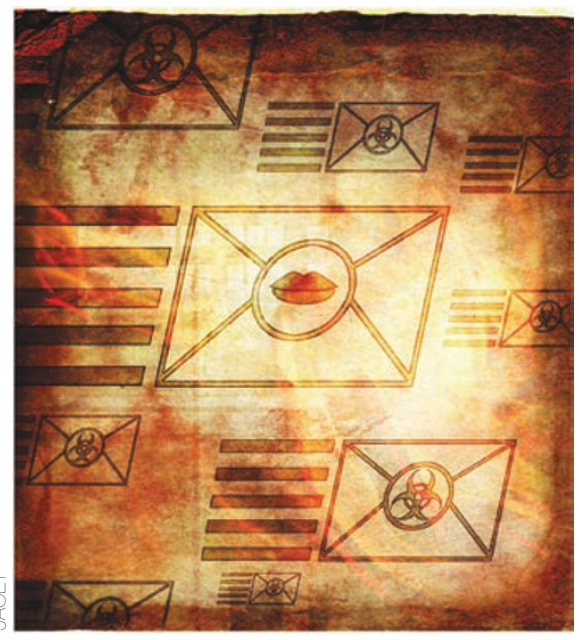

Knowing Clare to be considerably more computer-savvy than me, I waited for her to devise a solution. In the meantime, I tinkered some more with the life-support system while my spam folder grew inexorably.

When I woke up the next morning, I had a headache worthy of my last bottle of single malt. I gulped down a couple of aspirin to clear my head. Only then did I consider what Clare might do if confronted with a network so overwhelmed by spam it couldn't handle legitimate e-mails.

So I searched through the contents of my spam folder, read every one of the thousand-plus e-mails and diligently followed every link. Finally I found a signal buried in all that noise: an e-mail nominally offering a manhood enhancement, but actually directing me to a web page containing Clare's instructions for protecting the Far Side Array.

With typical gumption, Clare had retaliated against the botnet by hijacking its virus.
Having read to the end of Clare's instructions I clicked on one last link, which led me to her final thoughts on our brief, if necessarily distant, relationship.

Dearest George

I hate to end things this way, but Meridiani Base is way too quiet, like my Inbox. So I'm going for a walk.

Sorry!

Love, as ever.

Clare.

Needless to say, I shall miss her.

So that just leaves me with the Far Side Array to sort out. Solar-powered, autonomous and self-repairing, it will continue to function long after my death.

Aware that the SETI guys had been using the array to ping the Universe, Clare had vowed to keep the botnet's viruses safely quarantined inside Sol's heliosphere. Thus our neighbours would be spared a barrage of e-mails extolling the virtues of penile extensions, penny share options and fake Rolex implants. I can see her point, though I refute it utterly.

What Clare forgot, or chose to ignore, is that humanity's last botnet won the Interplanetary Information War. To the winner go the spoils!

It occurs to me that this is our first (and last) lovers' tiff. However, this is an argument Clare cannot win.

Her instructions told me how to isolate the Far Side Array from the network. Instead, I have taken down its firewall.

If Clare can hack the botnet's virus, then so, given time, can I. Although I lack her coding skills, knowing that the task can be done is half the battle. Assuming the base's life-support system holds out for long enough, I will learn how to clone the virus and incorporate my own payload.

My final act will be to switch the Far Side Array's mode from receive to transmit. Free at last, our viral progeny will roam the Universe, infecting ET's networks with their messages of love.

I can think of no finer epitaph for humanity.

\section{Vaughan Stanger}

Vaughan Stanger's science-fiction stories have been published in Postscripts, Interzone and Hub, among others. He is firmly convinced he'd have received more acceptances if only editors' e-mails could get through. 